\title{
MEMBANGUN KOMITMEN ORGANISASI BERBASIS PADA ISLAMIC \\ LEADERSHIP DAN KNOWLEDGE DONATING BAGI KARYAWAN KOPERASI SYARI'AH BMT KABUPATEN SEMARANG
}

\author{
Natoil \\ Prodi Manajemen STIE SEMARANG
}

\begin{abstract}
The purpose of this research is to test the influences of Islamic leadership, and knowledge donating, on organizational commitment moderated by spiritual motivation. Using these variables, the usage of these variables are able to solve the arising problem within employees sharia cooperatives BMT Kabupaten Semarang. Statement of this problem is how increase organizational commitment.

The samples size of this research is 80 employees sharia coopertives BMT Kabupaten Semarang. The results show that Islamic leadership, and knowledge donating, on organizational commitment moderated by spiritual motivation.

The effect of Islamic leadership on organizational commitment are significant; The effect of knowledge donating on organizational commitment are significant; spiritual motivation moderating influence knowledge donating on organizational commitment are significant.
\end{abstract}

Keywords: Islamic leadership, knowledge donating,spiritual motivation.and organizational commitment.

\begin{abstract}
ABSTRAK
Penelitian ini ditujukan untuk menguji pengaruh Islamic leadership dan knowledge donating terhadap komitmen organisasi yang dimoderasi spiritual motivasi. Sedangkan masalah dalam penelitian ini adalah bagaimana meningkatkan komitmen organisasi para karyawan koperasi syari'ah BMT di kabupaten semarang melalui Islamic leadership dan knowledge donating dengan dimoderasi spiritual motivasi.

Sampel penelitian ini adalah karyawan koperasi syari,ah BMT Kabupaten Semarang sejumlah 80 responden. Hasil analisis menunjukkan bahwa Islamic leadership dan knowledge donating berpengaruh signifikan terhadap komitmen organisasi dengan dimoderasi spiritual motivasi.

Temuan empiris tersebut mengindikasikan bahwa Islamic leadership berpengaruh signifikan terhadap komitmen organisasi; knowledge donating berpengaruh signifikan terhadap komitmen organisasi; spiritual motivasi memoderasi pengaruh knowledge donating terhadap komitmen organisasi.
\end{abstract}

Kata Kunci: Islamic leadership,knowledge donating,spiritual motivasi dan komitmen organisasi 


\section{Pendahuluan}

Komitmen organisasi adalah sebuah konstruksi global yang mencerminkan respon afektif dan kekuatan relatif dari seorang individu akan identifikasi dan keterlibatannya terhadap keseluruhan organisasi. Hal ini dimanifestasikan dengan adanya kepercayaan (identifikasi) dan penerimaan (internalisasi) yang kuat atas tujuan dan nilai nilai organisasi, kemauan untuk mengusahakan tercapainya kepentingan organisasi (keterlibatan kerja) dan keinginan yang kuat untuk mempertahankan kedudukan sebagai anggota organisasi (Mahdian dan Poor, 2014).

Membangun komitmen (commitment building) bukanlah pekerjaan mudah, dan merupakan pekerjaan besar yang harus dilakukan dengan kesabaran dan kearifan. Berbagai cara dapat dilakukan untuk meningkatkan komitmen organisasi, seperti yang diungkapkan Mahdian dan Poor, (2014), yang menjelaskan adanya The Want dan Need Factors yang berkontribusi terhadap peningkatan terbentuknya komitmen organisasi SDM. The Want factors ini berkaitan dengan komitmen afektif dan normatif, yang mengacu pada kedekatan emosional, identifikasi dan keterlibatan dalam organisasi. Sedangkan The Need factors berkaitan dengan komitmen berkelanjutan dan kerugian yang berhubungan dengan keluarnya SDM dari organisasi. Dari kedua faktor tersebut upaya membangun komitmen melalui kedekatan emosional mengacu pada The want factors akan merangsang terbentuknya perasaan individu yang memiliki loyalitas yang tinggi pada organisasi dan merasa menjadi bagian dari organisasi, sehingga akan tetap melanjutkan keberadaannya dalam organisasi.

Kepemimpinan merupakan salah satu faktor yang dapat mempengaruhi komitmen organisasi. Tanpa adanya kepemimpinan yang tepat dan pemberian motivasi dari atasan, maka komitmen yang ditunjukkan oleh SDM tidak dapat mendukung efektifitas sebuah organisasi, menjelaskan salah satu hal yang berkaitan dengan efektifitas sebuah kepemimpinan ditempat kerja, tidak terlepas dari sebuah nilai nilai spiritual. Oleh karena itu merupakan sebuah hal yang penting untuk menanamkan nilai moral spiritual pada seluruh SDM. Kepuasan terkait dengan terpenuhinya kebutuhan spiritual ditempat kerja akan memberikan 
pengaruh yang positif pada kesehatan manusiawi dan psikologis serta dapat dijadikan sebuah pondasi penerapan islamic leadership (Mahdian dan Poor, 2014).

Organisasi yang berhasil dalam mencapai tujuan serta mampu memenuhi tanggung jawab sosialnya akan sangat tergantung pada para manajernya (pimpinan). Bila pimpinan mampu melaksanakan dengan baik, sangat mungkin organisasi tersebut akan mencapai sasarannya. Suatu organisasi membutuhkan pemimpin yang efektif, yang mempunyai kemampuan mempengaruhi perilaku anggotanya atau anak buah. Jadi, seorang pemimpin atau kepala suatu organisasi akan diakui sebagai seorang pemimpin apabila ia dapat mempunyai pengaruh dan mampu mengarahkan bawahannya kearah pencapaian tujuan organisasi.

Kualitas dari pemimpin seringkali dianggap sebagai faktor terpenting dari keberhasilan atau kegagalan organisasi (Menon, 2002) demikian juga keberhasilan atau kegagalan suatu organisasi baik yang berorientasi bisnis maupun publik, biasanya dipersepsikan sebagai keberhasilan atau kegagalan pemimpin. Begitu pentingnya peran pemimpin sehingga isu mengenai pemimpin menjadi faktor yang menarik perhatian para peneliti bidang perilaku keorganisasian. Hal ini akan membawa konsistensi bahwa setiap pemimpin berkewajiban memberikan perhatian yang sungguh-sungguh untuk membina, menggerakkan, mengarahkan semua potensi karyawan dilingkungannya agar terwujud volume dan beban kerja yang terarah pada tujuan. Pimpinan perlu melakukan pembinaan yang sungguh-sungguh terhadap karyawan agar dapat meningkatkan kinerja dan menimbulkan kepuasan kerja yang tinggi. Ketika pemimpin menunjukkan kepemimpinan yang baik, para karyawan akan berkesempatan untuk mempelajari perilaku yang tepat untuk berhadapan dengan pekerjaan mereka. Demikian pula halnya dengan birokrasi publik, pemimpin memegang peranan yang sangat strategis. Berhasil atau tidaknya birokrasi publik menjalankan tugas-tugasnya sangat ditentukan oleh kualitas pimpinannya, karena kedudukan pemimpin sangat mendominasi semua aktivitas yang dilakukan.

Bergesernya kebutuhan organisasi dari kebutuhan material ke informasi merupakan salah satu pendorong maraknya implementasi knowledge donating. Di 
masa lampau organisasi bergantung pada sumber daya alam, tenaga kerja (labor), mesin-mesin, dan kapital. Akan tetapi sekarang organisasi sangat bergantung pada kemampuan knowledge worker yang mereka miliki. Knowledge aset telah menggeser aset-aset berupa tanah, buruh, dan kapital. Yam et al., (2012) menyatakan bahwa knowledge donating mempunyai pengaruh signifikan terhadap komitmen organizational, namun Aziz et al., (2013) menyatakan bahwa knowledge donating tidak berpengaruh signifikan terhadap komitmen organisasi.

Faktor penting yang lain dalam membangun komitmen adalah kepemimpinan, karena BMT adalah lembaga keuangan Islam maka kepemimpinan Islam merupakan factor yang perlu mendapatkan perhatian. Walau demikian masih ada hasil penelitian yang berbeda, Moten, (2011) menyatakan bahwa islamic leadership berpengaruh signifikan terhadap komitmen organisasi, sedangkan Mahdian dan Poor, (2014) menyatakan bahwa islamic leadership tidak berpengaruh signifikan terhadap komitmen organisasi.

Komitmen yang kuat memerlukan adanya motivasi yang kuat, dalam BMT, motivasi spiritual perlu diperhatikan. Anshari (1993) menjelaskan bahwa motivasi spiritual seorang muslim terbagi menjadi tiga: motivasi akidah, motivasi ibadah dan motivasi muamalat. Motivasi akidah adalah keyakinan hidup, yaitu pengikraran yang bertolak dari hati. Jadi, motivasi akidah dapat ditafsirkan sebagai motivasi dari dalam yang muncul akibat kekuatan akidah tersebut. Poulsen (2013) mengemukakan bahwa motivasi islam untuk bekerja ini sangat penting bagi tinggi rendahnya pengaruh knowledge donating terhadap komitmen organizarional. Tanpa adanya motivasi dari para SDM untuk bekerja sama bagi kepentingan organisasi maka tujuan yang telah ditetapkan tidak akan tercapai. Sebaliknya apabila terdapat motivasi yang tinggi dari para SDM, maka hal ini merupakan suatu jaminan atas keberhasilan organisasi dalam meningkatkan komitmen organisasinya. Poulsen (2013) menunjukkan bahwa spiritual motivation memoderasi pengaruh knowledge donating terhadap komitmen organisasi, namun Gagne (2009) tidak menunjukkan bahwa spiritual motivation memoderasi pengaruh knowledge donating terhadap komitmen organisasi. 


\section{Masalah Penelitian}

Permasalahan dalam ini karena adanya gap antara SDM lama dengan SDM baru, dimana pada SDM baru mempunyai kecenderungan dalam bekerja mencari profit yang besar namun sering mengindahkan prinsip-prinsip syariah sesuai dengan majelis keluarga utama, dimana implementasi yang dilakukan hanya semacam ritualitas namun pemahaman yang kurang, selain itu ada indikasi komitmen organisasional dari SDM yang rendah dimana ada beberapa SDM berpindah kerja ke bank konvensional yang tidak menjalankan prinsip syariah dengan iming-iming gaji yang besar, selain itu SDM baru mempunyai kecenderungan kurang memahami visi misi dari awal pembentukan BMT. Rumusan masalah dalam penelitian ini adalah bagaimana meningkatkan komitmen organisasional melalui knowledge donating dan kepemimpinan islam dengan dimoderasi spiritual motivation?.

\section{Kajian Teoritis}

1. Komitmen Organisasional

Komitmen organisasional secara umum dapat diartikan sebagai keterikatan SDM pada organiasasi dimana SDM tersebut bekerja. Komitmen dibutuhkan oleh organisasi agar sumber daya manusia yang komputen dalam organisasi dapat terjaga dan terpelihara dengan baik. Komitmen organisasi didefinisikan sebagai pengukur kekuatan SDM yang berkaitan dengan tujuan dan nilai organisasi (Nursyamsi, 2012).

Robbins (2008) membagi variabel komitmen organisasional dalam tiga katagori yaitu: (1) karakteristik personel dari setiap anggota organisasi yang meliputi umur, pendidikan, jenis kelamin, dan kebutuhan akan pencapaian; (2) karakteristik yang berhubungan dengan pekerjaan yang terdiri dari beberapa variabel seperti penekanan peran (konflik dan ketidakjelasan peran) serta (karakteristik tugas dan pengalaman kerja yang meliputi variabel seperti sikap Islamic leadership (inisiatif dari organisasi dan pertimbangan dari pimpinan) serta struktur organisasi (formalisasi dan pertisipasi dalam pengambilan keputusan). Mengingat fokus penelitian ini adalah pada faktor-faktor organisasi maka 
penelitian ini hanya dibatasi kepada karakteristik-karakteristik yang berhubungan dengan pekerjaan serta pengalaman kerja. Meskipun kedua variabel tersebut diharapkan berkaitan dengan sampel penelitian yang diberikan, pada saat yang bersamaan, sangatlah mungkin bila pekerja yang memegang kepercayaan positif dan cinta kepada organisasi serta tujuan dan nilainya, tetapi tidak suka dengan pelaksanaan aspek-aspek tertentu pada pekerjaan tertentu di organisasi tersebut dan sebaliknya.

Komitmen organisasional didasarkan pada perilaku yang terutama berasal dari ketidakleluasaan menggunakan ketrampilan pekerja sehingga meninggalkan organisasi yang mengikatnya. Saat komitmen dicontohkan sebagai fungsi kepercayaan terhadap organisasi dan pengalaman kerja, karakteristrik organisasi harusnya menjadi faktor yang mempengaruhi kepercayaan SDM terhadap organisasi dan oleh karena itu pada level komitmen SDM; karakteristik kerja harusnya menjadi faktor utama yang mempengaruhi kepuasan kerja dan kinerja dari SDM.

\section{Islamic leadership}

Islamic leadership (Sumarno, 2005) adalah pemimpin atau manajer yang berorentasi peningkatan kemampuan berfokus pada pengembangan keterampilanketerampilan SDM untuk meningkatkan kualitas kinerja SDM. Sikap seorang pemimpin yang selalu berusaha menegakkan kebenaran dan berpegang teguh berdasarkan tuntunan ajaran Islam, maka akan disegani, dihormati dan dipatuhi. Pemimpin yang mencintai kebenaran hanya takut pada Allah SWT, sebagai sumber dan pemilik kebenaran yang Maha Sempurna. Sedangkan pemimpin yang menentang kebenaran justru akan dikategorikan Allah SWT sebagai orang yang termasuk golongan kafir (Khan, 2014).

Islamic leadership dalam setiap organisasi berbeda tergantung pada spesifikasinya. Perbedaan ini disebabkan oleh jenis organisasi, situasi sosial dalam organisasi dan jumlah anggota kelompok dalam organisasi tersebut. Peran dari manajemen organisasi dapat diidentifikasikan sebagai membangun suatu kebijakan dalam organisasi, membangun dan menyebar tujuan dari kebijakan, menyediakan sumber daya yang ada, menyediakan pelatihan orientasi pada 
permasalahan dan menstimulasi pengembangan atau kemajuan dari organisasi (Juran dan Gyrna, 1993).

Kepemimpinan Islam yaitu kepemimpinan yang membentuk values, attitude, behavior yang dibutuhkan untuk memotivasi diri sendiri dan orang lain secara intrinsic motivation, sehingga menggapai rasa spiritual survival yang didasarkan pada agama Islam. Istilah yang paling dekat dengan kepemimpinan Islam yaitu Akhlaq. Di dalam Al Quran istilah yang secara langsung berhubungan dengan kepemimpinan Islam adalah al-khuluq. Al-khuluq berasal dari kata dasar khaluqa-khuluqan, yang berarti, tabi"at, budi pekerti, kesatriaan, keprawiraan. Islam memberikan tuntunan akidah tauhid, dasar tauhid ini dipadu dengan contoh yang diberikan Rasulullah yang diharapkan akan menghasilkan manusia yang memiliki akhlak atau etika yang baik. Akhlak yang dicontohkan oleh Rasullullah ini didasarkan pada petunjuk dari al-Qur"an.

Mosadeghrad dan Fedosi, (2013) menyatakan bahwa pimpinan mampu meningkatkan komitmen organisasional. May et al., (2009) dalam penelitiannya di Malaysia menunjukkan bahwa komitmen SDM akan meningkat ketika pimpinan mampu meningkatkan potensi bawahan untuk lebih berprestasi. Keskes, (2014) dalam penelitiannya menyatakan bahwa peran pimpinan sangat penting dalam meningkatkan komitmen bawahan untuk bekerja lebih bagi organisasi. Raja dan Palanichamy, (2014) menyatakan bahwa Islamic leadership mempunyai pengaruh positif terhadap komitmen organizational.

H1: Islamic leadership berpengaruh positif terhadap komitmen organisaional

\section{Knowledge donating}

Knowledge donating yaitu perilaku mengkomunikasikan modal intelektual yang dimiliki seseorang kepada yang lainnya (Sutton, 2006). Secara konseptual Knowledge donating dapat didefinisikan sebagai tingkatan sejauh mana seseorang secara aktual melakukan knowledge donating. Knowledge donating dapat pula dipahami sebagai perilaku dimana seseorang secara sukarela menyediakan akses terhadap orang lain mengenai knowledge dan pengalamannya. Tipe knowledge 
donating dapat bervariasi mengikuti pemahaman terhadap knowledge itu sendiri. Knowledge dapat dipahami sebagai aset individu atau organisasi yang bersifat tacit maupun explicit. Explicit knowledge adalah knowledge yang telah terdokumentasikan, mudah dimodifikasi dan diartikulasikan serta bersifat objektif. Sebaliknya, tacit knowledge adalah knowledge yang belum terdokumentasikan dan melekat di dalam diri seseorang, tidak mudah untuk diungkapkan dan bersifat subjektif (Levin et al., 2014). Berbagi pengetahuan baru

Davoudi dan Fartash, Neurink, (2012) menyatakan bahwa SDM yang mempunyai knowledge donating yang kuat akan memberikan seluruh kemampuannya untuk kemajuan organisasi. Neurink, (2013) menyatakan bahwa SDM yang bersedia berbagi dengan pengetahuan mampu meningkatkan komitmen organisasional.

$\mathrm{H} 2$ : Knowledge donating berpengaruh positif terhadap komitmen organisaional

\section{Spiritual Motivation}

Maslow mengakui bahwa untuk mencapai aktualisasi diri sebagai tingkatan motivasi yang paling tinggi adalah dengan cara memuaskan empat kebutuhan yang berada pada tingkatan yang ada di bawahnya. Orang yang mengaktualisasikan diri lebih didorong oleh metamotivasi. Konsep metamotivasi merupakan pendekatan humanistik yang mengakui eksistensi agama. Mystical atau peak experience merupakan bagian dari metamotivasi yang memberikan gambaran pada pengalaman keagamaan. Pada kondisi ini manusia merasakan adanya pengalaman keagamaan yang sangat dalam. Pribadi (self) lepas dari realitas fisik dan menyatu dengan kekuatan transendental. Tingkatan ini adalah bagian dari kesempurnaan manusia. Oleh karenanya, Maslow membagi dua klasifikasi motivasi: motivasi primer dan motivasi spiritual. Kebutuhan spiritual merupakan kebutuhan yang fitri yang pemenuhannya tergantung pada kesempurnaan manusia dan kematangan individu. Nampaknya ada kontribusi yang besar tentang pentingnya spiritual seseorang yang berpengaruh pada psikis seseorang dalam bekerja (Muafi, 2003). 
Selanjutnya, Anshari (1993) menjelaskan bahwa motivasi spiritual seorang muslim terbagi menjadi tiga: motivasi akidah, motivasi ibadah dan motivasi muamalat. Motivasi akidah adalah keyakinan hidup, yaitu pengikraran yang bertolak dari hati. Jadi, motivasi akidah dapat ditafsirkan sebagai motivasi dari dalam yang muncul akibat kekuatan akidah tersebut. Muafi, (2003) lebih menyebut motivasi akidah tersebut sebagai sikap intrinsik. Dimensi akidah ini menunjuk pada seberapa besar tingkat keyakinan muslim terhadap ajaran-ajaran yang bersifat fundamental dan dogmatik. Isi dimensi keimanan mencakup iman kepada Allah, para Malaikat, Rasul-Rasul, kitab Allah, surga dan neraka, serta qadha dan qadar. Ibadah merupakan tata aturan Illahi yang mengatur hubungan ritual langsung antara hamba Allah dengan Tuhannya yang tata caranya ditentukan secara rinci dalam Al Qur'an dan Sunnah Rasul (Anshari, 1993). Sedangkan motivasi ibadah merupakan motivasi yang tidak pernah dilakukan oleh orang yang tidak memiliki agama, seperti sholat, doa, dan puasa. Ibadah selalu bertitik tolak dari aqidah. Jika dikaitkan dengan kegiatan bekerja, ibadah masih berada dalam taraf proses, sedangkan output dari ibadah adalah muamalat.

H3: Spiritual motivation memoderasi pengaruh knowledge donating terhadap komitmen organisasional

\section{Metodologi}

Jenis data yang digunakan dalam penelitian ini terdiri dari data primer dan data sekunder. Data primer adalah informasi yang diperoleh secara langsung dari pihak yang bersangkutan dan masih harus diolah lagi sebelum akhirnya dipergunakan dalam penelitian. Data primer yang diperlukan dalam penelitian ini adalah data yang berkaitan dengan Islamic leadership, knowledge donating, spiritual motivation, dan komitmen organisassi. jenis penelitian yang digunakan adalah "Explanatory research" atau penelitian yang bersifat menjelaskan, artinya penelitian ini menekankan pada hubungan antar variabel penelitian dengan menguji hipotesis uraiannya mengandung deskripsi tetapi fokusnya terletak pada hubungan antar variable. 
Populasi dalam penelitian ini adalah karyawan yang bekerja di BMT anggota PBMTI korda Kabupaten Semarang sejumlah 80 karyawan. Berdasarkan rumus diperoleh sampel sejumlah 76,3 dan dibulatkan menjadi 80 sampel, diambil dari karyawan koperasi syari'ah BMT masing-masing koperasi syari'ah BMT diwakili 8 responden, sehingga terpenuhi sampel sejumlah 80 responden. Teknik pengambilan sampel menggunakan propotional random sampling dengan masingmasing koperasi syari'ah BMT dari 10 koperasi syari'ah BMT di kabupaten semarang diambil 8 responden untuk memenuhi 80 responden yang diperlukan dalam penelitian ini.

Dalam penelitian ini terdapat empat variabel yaitu Knowledge donating, Islamic leadership, Komitmen organisasional, dan Spritual motivation yang didefinisikan sebagai berikut:

a. Knowledge donating yaitu perilaku mengkomunikasikan modal intelektual yang dimiliki seseorang kepada yang lainnya.

b. Islamic leadership yaitu kepemimpinan yang membentuk values, attitude, behavior yang dibutuhkan untuk memotivasi diri sendiri dan orang lain.

c. Komitmen organisasional yaitu keterikatan SDM pada organiasasi dimana SDM tersebut bekerja.

d. Spritual motivation adalah motivasi untuk merangsang SDM secara spiritual.

Data dikumpulkan dengan metode kuesioner, yaitu suatu metode pengumpulan data dengan memberikan daftar pertanyaan atau kuesioner secara langsung kepada para responden. Setiap responden diminta pendapatnya dengan memberikan jawaban dari pernyataan-pernyataan yang diajukan. Kuesioner yang digunakan dalam penelitian ini menggunakan skala likert untuk menelaah seberapa kuat subjek setuju atau tidak setuju dengan pernyataan pada alternatif jawaban terdiri dari lima buah jawaban pada setiap pernyataan. Sehingga responden dapat memilih salah satu jawaban yang paling mendekati pendapatnya.

Analisis yang digunakan dalam penelitian ini adalah regressi berganda dengan Moderating Regression Analysis (MRA) dengan persamaan sebagai berikut :

$$
\mathrm{Y}=\beta 1 \mathrm{X} 1+\beta 2 \mathrm{X} 2+\beta 3 \mathrm{X} 2 \mathrm{X} 3+e
$$


Keterangan:

$$
\begin{array}{ll}
\beta 1, \beta 2, \beta 3 & =\text { Koefisien parameter variabel independen } \\
e & =\text { error sampling } \\
\mathrm{X} 3 & =\text { Spiritual motivation } \\
\mathrm{Y} & =\text { Komitmen organizational } \\
\mathrm{X} 1 & =\text { Islamic leadership } \\
\mathrm{X} 2 & =\text { Knowledge donating }
\end{array}
$$

Juga telah dilakukan uji kulitas data yaitu uji validitas dan reliabilitas serta dilakukan uji asumsi klasik meliputi normalitas, heterokedastisitas, dan multikolinieritas

\section{Pembahasan}

a. Uji Kualitas Data

1. Uji Validitas

Pengujian validitas dilakukan dengan menggunakan metode Analisis Faktor. Nilai Corrected item total correlation yang berada di atas r tabel yaitu sebesar 0,4000 menunjukkan sebagai 32 item yang valid. Pengujian validitas selengkapnya dapat dilihat pada Tabel 1 berikut ini.

Tabel 1

Hasil Pengujian Validitas

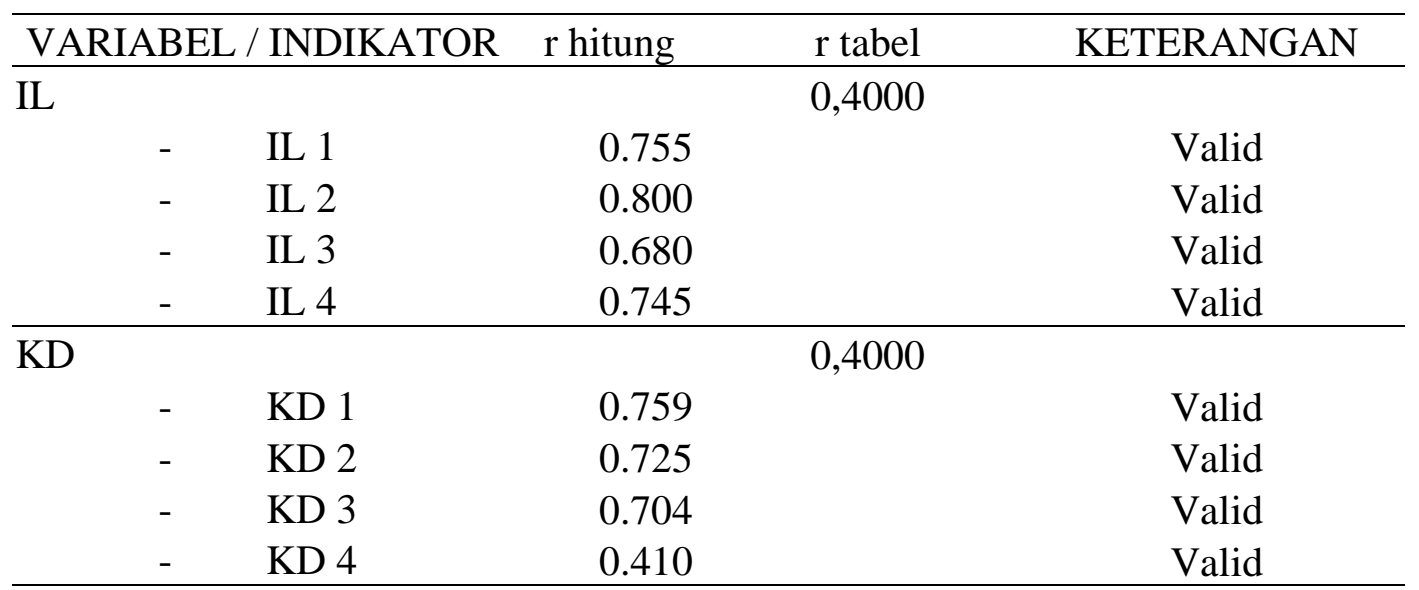




\begin{tabular}{|c|c|c|c|}
\hline \multirow[t]{7}{*}{ SM } & \multicolumn{3}{|c|}{0,4000} \\
\hline & SM 1 & 0.713 & Valid \\
\hline & SM 2 & 0.755 & Valid \\
\hline & SM 3 & 0.757 & Valid \\
\hline & SM4 & 0.709 & Valid \\
\hline & SM5 & 0.554 & Valid \\
\hline & SM6 & 0.457 & Valid \\
\hline \multirow[t]{5}{*}{$\mathrm{KO}$} & & & \\
\hline & KO 1 & 0.750 & Valid \\
\hline & KO 2 & 0.803 & Valid \\
\hline & KO 3 & 0.713 & Valid \\
\hline & KO 3 & 0.586 & Valid \\
\hline
\end{tabular}

Sumber : Hasil output regressi, 2018

Tabel 4.1 menunjukkan bahwa semua indikator yang digunakan untuk mengukur variabel-variabel yang digunakan dalam penelitian ini mempunyai nilai loading factor yang lebih besar dari 0,4. Dari hasil tersebut menunjukkan bahwa semua indikator tersebut adalah valid, artinya indikator yang digunakan dapat menjelaskan variabelnya.

\section{Uji Reliabilitas}

Uji Reliabilitas digunakan untuk mengukur seberapa tinggi instrumen dapat dipercaya dapat diandalkan. Suatu instrumen yang dikatakan reliabel apabila memenuhi nilai cronbach alpha> 0,6 berikut hasil pengolahan data dari seluruh variabelnya sebagai berikut :

Tabel 4.2

Uji Reliabilitas

\begin{tabular}{|c|c|c|}
\hline \multicolumn{2}{|c|}{ Variabel cronbach alpha } & \multirow{2}{*}{$\begin{array}{c}\text { Keterangan } \\
\text { Reliabel }\end{array}$} \\
\hline IL & 0,882 & \\
\hline $\mathrm{KD}$ & 0,820 & Reliabel \\
\hline SM & 0,861 & Reliabel \\
\hline KO & 0,863 & Reliabel \\
\hline
\end{tabular}

Sumber : Hasil output regressi, 2018

Berdasarkan table 4.2 dapat disimpulkan bahwa semua indikator memenuhi kriteria reliabel. Hai ini ditunjukkan oleh nilai cronbach alpha IL 
sebesar 0,882, nilai cronbach alpha KD sebesar 0,820, nilai cronbach alpha SM sebesar 0,861 dan nilai cronbach alpha KO sebesar 0,863 memiliki nilai cronbach alpha lebih dari 0,6, artinya kuesioner layak untuk digunakan karena mempunyai tingkat kehandalan yang baik. Hal ini menunjukkan bahwa kuesioner yang dibuat relevan dengan kondisi di BMT se Kabupaten Semarang sehingga kuesioner penelitian handal.

\section{b. Uji Asumsi Klasik}

1. Normalitas Data

Uji asumsi klasik normalitas residual dengan menggunakan analisis grafik yang melihat grafik histogram yang membandingkan antara data observasi dengan distribusi yang mendekati distribusi normal. Dengan melihat tampilan grafik histogram, dapat disimpulkan bahwa grafik histogram memberikan pola distribusi yang mendekati normal. Berdasarkan normal probability plot terlihat titik-titik menyebar di sekitar garis diagonal serta penyebarannya mengikuti arah garis diagonal. Berdasarkan grafik normal plot menunjukkan bahwa model regresi layak dipakai dalam penelitian ini karena memenuhi asumsi normalitas. Hasil uji normalitas tersebut menunjukkan hasil dengan data yang berdistribusi normal, sehingga sampel tersebut memenuhi syarat untuk dilakukan penelitian lebih lanjut.

\section{Uji Multikoliniearitas}

Untuk mendeteksi ada tidaknya gejala multikoliniearitas antar variabel independen digunakan variance inflation factor (VIF). Berdasarkan Tabel 4.3tidak terdapat variabel independen yang mempunyai nilai VIF > 5, artinya ketiga variabel independen tersebut tidak terdapat hubungan multikolinieritas. 
Tabel 4.3

Hasil Uji Multikoliniearitas

Coefficients $^{\mathrm{a}}$

\begin{tabular}{|c|c|c|c|}
\hline \multirow{2}{*}{\multicolumn{2}{|c|}{ Model }} & \multicolumn{2}{|c|}{ Collinearity Statistics } \\
\hline & & Tolerance & VIF \\
\hline \multirow[t]{3}{*}{1} & IL & 0.290 & 3.449 \\
\hline & $\mathrm{KD}$ & 0.110 & 9.094 \\
\hline & Moderate & 0.148 & 6.761 \\
\hline
\end{tabular}

a. Dependent Variabel: KO

Sumber : Hasil output regressi, 2018

3. Uji Heteroskedastisitas

Uji heteroskedastisitas untuk menguji apakah terdapat pengaruh variabel independen terhadap variabel residualnya. Variabel residual adalah variabel lain selain komitmen organisasional. Berdasar output SPSS versi 11.5 maka hasil uji heteroskedastisitas dapat ditunjukkan dalam tabel 4.4 sebagai berikut:

Tabel 4.4

Hasil Uji Heteroskedastisitas

Coefficients $^{\mathrm{a}}$

\begin{tabular}{|c|c|c|c|c|c|c|}
\hline & \multirow[t]{2}{*}{ Model } & \multicolumn{2}{|c|}{$\begin{array}{l}\text { Unstandardized } \\
\text { Coefficients }\end{array}$} & \multirow{2}{*}{$\begin{array}{c}\text { Standardized } \\
\text { Coefficients } \\
\text { Beta }\end{array}$} & \multirow[t]{2}{*}{$\mathrm{t}$} & \multirow[t]{2}{*}{ Sig. } \\
\hline & & $\mathrm{B}$ & Std. Error & & & \\
\hline \multirow[t]{4}{*}{1} & (Constant) & .672 & .182 & & 3.683 & .000 \\
\hline & IL & -.014 & .080 & -.036 & -.170 & .866 \\
\hline & $\mathrm{KD}$ & -.098 & .138 & -.244 & -.711 & .479 \\
\hline & Moderate & .023 & .024 & .288 & .972 & .334 \\
\hline
\end{tabular}

a. Dependent Variabel: ABSRES

Sumber : Hasil output regressi, 2018

c. Pengujian Hipotesis

1. Uji t

Analisis jalur dilakukan untuk menguji ada tidaknya pengaruh variabel independen terhadap variabel dependen dengan menggunakan variabel mediasi. Berdasarkan perhitungan analisis jalur dengan SPSS, hasilnya tampak pada Tabel 4.5 
Tabel 4.5

Hasil Estimasi Koefisien Regressi

\begin{tabular}{cclcccc}
\hline No & $\begin{array}{r}\text { Variabel } \\
\text { Terikat }\end{array}$ & Variabel Bebas & $\mathrm{B}$ & $\begin{array}{c}\mathrm{t} \\
\text { hitung }\end{array}$ & Sign & Keterangan \\
\hline 1 & $\begin{array}{l}\text { Komitmen } \\
\text { Organisasi }\end{array}$ & $\begin{array}{l}\text { Islamic } \\
\text { Leadership }\end{array}$ & 0.318 & 2.316 & 0.023 & Ha Diterima** \\
2 & $\begin{array}{l}\text { Komitmen } \\
\text { Organisasi }\end{array}$ & $\begin{array}{l}\text { Knowledge } \\
\text { Donating } \\
3\end{array}$ & 0.254 & 2.037 & 0.046 & Ha Diterima** \\
& $\begin{array}{l}\text { Komitmen } \\
\text { Organisasi }\end{array}$ & $\begin{array}{l}\text { Kemoderasi } \\
\text { KD }\end{array}$ & 0.731 & 3.800 & 0.000 & Ha Diterima* \\
\hline
\end{tabular}

Sumber : Hasil output regressi, 2018

Keterangan: * signifikan pada level $1 \%$

** signifikan pada level $5 \%$

\section{Uji F}

Nilai $\mathrm{F}$ hitung diperoleh 35, $613(\operatorname{sig} \alpha=1 \% *$ ) menunjukkan model penelitian ini layak untuk diteliti. Berdasarkan Tabel 4.12 diatas, maka persamaan jaluradalah sebagai berikut:

$$
\mathrm{KO}=0,318 \mathrm{IL}+0,254 \mathrm{KD}+0,731 \mathrm{KD} * \mathrm{SM}
$$

Variabel Islamic leadership, dan knowledge donating mempunyai tanda positif, artinya jika variabel tersebut meningkat maka variabel terikat yaitu: komitmen organisasi akan meningkat.

\section{Koefisien Determinasi}

Hasil penelitian koefisien determinasi pada regressi adalah dapat dijelaskan pada Tabel 4.5 berikut:.

Tabel 4.5

Model Pengukuran

\begin{tabular}{ccccc}
\hline No & $\begin{array}{c}\text { Variabel } \\
\text { Tergantung }\end{array}$ & Variabel Bebas & $\mathrm{R}^{2}$ \\
\hline 1 & $\begin{array}{l}\text { Komitmen } \\
\text { organisasi }\end{array}$ & $\begin{array}{l}\text { Islamic leadership, Knowledge donating } \\
\text { dan Spiritual motivasi }\end{array}$ & 0,568 \\
\hline Sumber: Output Hasil Analisis Regressi Berganda (2018) & &
\end{tabular}


Dari tabel diatas dapat menunjukkan nilai R-Square untuk setiap variabel dependenuntuk variabel kinerja bisnis diperoleh sebesar 0,568. Hasil ini menunjukkan bahwa variabel komitmen organisasi dipengaruhi Islamic leadership Knowledge donating dan Spiritual motivasi sebesar 43,2\% sisanya dipengaruhi oleh variabel lainnya yang tidak diteliti.

\section{Pembahasan}

\section{Pengaruh Islamic Leadership terhadap Komitmen Organisasi}

Hasil penelitian menunjukkan bahwa Islamic leadership berpengaruh positif signifikan terhadap komitmen organisasi, artinya semakin baik kepemimpinan (Islam) akan mampu meningkatkan komitmen organisasi. Pemimpin yang menekankan pada akhlaq, berbasis pada syariat agama, memimpin adalah melaksanakan amanah, dan mementingkan umat mampu meningkatkan komitmen organisasi, dengan pemimpin yang mempunyai Islamic keadership yang kuat membuat karyawan terus menjadi bagian organisasi.

Di sisi lain, kemampuan pemimpin dalam menggerakkan dan memperdayakan SDM akan mempengaruhi komitmen organisasi. Peran kepemimpin memiliki dampak signifikan terhadap sikap, perilaku dan kinerja SDM. Efektivitas pemimpin dipengaruhi karakteristik bawahannya dan terkait dengan proses kom unikasi yang terjadi antara pemimpin dan bawahan. Pemimpin dikatakan tidak berhasil apabila tidak dapat memotivasi, menggerakkan dan memuaskan SDM pada suatu pekerjaan dan lingkungan tertentu. Peran pemimpin adalah mendorong bawahan supaya memiliki kompetensi dan kesempatan berkembang dalam megantisipasi setiap tantangan dan peluang dalam bekerja (Mosadeghrad dan Fedosi, 2013). Hasil penelitian ini mendukung penelitian Mosadeghrad dan Fedosi, (2013) dan Keskes, (2014).

\section{Pengaruh Knowledge Donating terhadap Komitmen Organisasi}

Hasil penelitian menunjukkan bahwa knowledge donating berpengaruh positif signifikan terhadap komitmen organisasi, artinya semakin baik knowledge donating akan mampu meningkatkan komitmen organisasi. Pimpinan yang mau 
berbagi pengetahuan yang mencakup berbagi pengetahuan baru, berbagi informasi baru tentang pekerjaan, perhatian kepada rekan kerja, dan berbagi cerita tentang pekerjaan, akan dapat membuat karyawan untuk terus menjadi bagian dari organisasi.

Knowledge donating (berbagi pengetahuan) atau berbagi pengetahuan sangat penting dalam manajemen pengetahuan antar karyawan baik internal maupun eksternal. Neurink, (2013) menyatakan bahwa SDM yang bersedia berbagi dengan pengetahuan mampu meningkatkan komitmen organisasi. Hasil penelitian ini mendukung penelitian Neurink, (2013).

3. Motivasi Spiritual Memoderasi Pengaruh Knowledge Donating terhadap Komitmen Organisasi

Hasil penelitian menunjukkan bahwa spiritual motivation memperkuat pengaruh knowledge donating terhadap komitmen organisasi, artinya semakin baik spiritual motivation akan mampu meningkatkan pengaruh knowledge donating terhadap komitmen organisasi. Spiritual motivation semakin tinggi, maka komitmen organisasi semakin tinggi spiritual motivation akan mendukung pimpinan untuk mau mengevaluasi pekerjaan untuk kepentingan bawahan, dengan menyadari bahwa kerja adalah ibadah, mencari riski adalah ibadah, dimana hal tersebut akan membuat pimpinan untuk memberikan seluruh kemampuannya untuk kepentingan organisasi.

Spiritual motivation berpengaruh positif terhadap komitmen afektif, berdasarkan konsep fitrah Al-Ghazâli berkaitan erat dengan pembahasan tentang motivasi. Untuk menjelaskan motivasi perilaku manusia, Al-Ghazâli menyuguhkan konsep syahwat sebagai motivasi mendekat (al-sabab al-dâkhili) dan ghadlab sebagai motivasi menjauh (al-sabab al-khâriji).Pemahaman terhadap hakekat manusia menurut Al-Ghazâli melalui pendekatan tasawuf memiliki pandangan, yaitu memandang manusia sebagai makhluk yang memiliki potensipotensi baik dan mampu diaktualisasikan sehingga mencapai manusia sempurna (al-insân al-kamîl).Kebutuhan spiritual merupakan kebutuhan yang fitri yang pemenuhannya tergantung pada kesempurnaan manusia dan kematangan individu. 
Nampaknya ada kontribusi yang besar tentang pentingnya spiritual seseorang yang berpengaruh pada psikis seseorang dalam bekerja (Muafi, 2003).

Ada tiga kata kunci dalam memahami konsep Islam tentang manusia, yaitu basyar, insân, fitrah, dan nafs, dan ruh. Konsep basyar menunjukkan posisi manusia sebagai makhluk biologis yang memerlukan kebutuhan dasar (physiological needs). Sedangkan konsep insân menunjukkan bahwa manusia adalah totalitas yang memiliki fisik dan psikis, badaniah dan ruhaniah, individualistik, khas, unik, berbeda antara manusia satu dengan yang lainya. Sementara nafs dan ruh merupakan tentara hati manusia (junûd al-qalb). Hati manusia ini telah memiliki potensi yang disebut fitrah. Hasil penelitian ini mendukung penelitian Poulsen (2013).

\section{Kesimpulan}

Berdasarkan hasil analisis dan pembahasan dapat diambil kesimpulan sebagai berikut:

1. Islamic leadership berpengaruh positif signifikan terhadap komitmen organisasi, artinya semakin baik kepemimpinan (Islam) akan mampu meningkatkan komitmen organisasi. Dalam rangka meningkatkan komitmen organisasi dari SDM koperasi syari'ah BMT untuk memperbaiki kepemimpinan

2. Knowledge donating berpengaruh positif signifikan terhadap komitmen organisasi, artinya semakin baik knowledge donating akan mampu meningkatkan komitmen organisasi. Untuk meningkatkan komitmen SDM terhadap organisasi, pimpinan mau memberikan pengetahuannya kepada bawahan.

3. Moderasi spiritual motivation memperkuat pengaruh knowledge donating terhadap komitmen organisasi, artinya semakin baik spiritual motivation akan mampu meningkatkan pengaruh knowledge donating terhadap komitmen organisasi. Dalam rangka meningkatkan komitmen organisasi dari SDM koperasi syari'ah BMT kabupaten semarang, pimpinan bersedia mengevaluasi pekerjaan untuk kepentingan bawahan, dengan menyadari 
bahwa kerja adalah ibadah, mencari riski adalah ibadah, dimana hal tersebut akan membuat pimpinan untuk memberikan seluruh kemampuannya untuk kepentingan organisasi.

\section{Daftar Pustaka}

Davoudi, Seyed Mehdi Mousavi, dan Kiarash Fartash, (2012), "The impact of knowledge sharing on organizational commitment of employees," Pacific Bussiness Review International

Ghozali, 2011, Aplikasi analisis Multivariate dengan Program SPSS, Badan Penerbit UNDIP, Semarang.

Hsiu Fen Lin, (2013), "Knowledge sharing and firm innovation capability: an empirical study," International Journal of Manpower

Jian, Zhaoquan; dan Chen Wang, (2013), "The impact of network competence, knowledge sharing on service innovation performance: moderating role of relationship quality," Journal of Industrial Engineering and Management

Keskes, Imen, (2013), "Relationship between leadership styles dimmension of employee organizational commitment," OmniaScience

Khan, Adalat, (2014), "Islamic leadership principles," Mina Management Institute

Levin, Daniel Z; Rob Cross; Lisa C Abrams; dan Eric L Lesser, (2014), "Trust and Knowledge sharing: A critical combination," IBM Institute for Knowledge Based Organizations

Megan Lee Endres; Steven P Endres; Sanjib K Chowdury; dan Intakhab Alam, (2007), "Tacit knowledge sharing, self efficacy theory and application to the open source community." Journal of Knowledge Management

Mosadeghrad, Ali Mohammad; dan Masoud Ferdosi, (2013), "Leadership, job satisfaction, and organizational commitment in healthcare sector," Original Paper

Neurink, Denise, (2013), “Knowledge Sharing From a Differente Approach," University of Twente 
Nursyamsi, Idayanti, (2014), "Pengaruh Kepemimpinan, Pemberdayaan dan Stres Kerja Terhadap Komitmen Organisasional serta dampaknya terhadap Kinerja Dosen," Conference in Business, Accounting, and Management (CBAM)

Ogoemeka; Helen Obioma, (2014), "Effects of peer collaboration on academic self efficacy belief and social competence of students with visual impairment," The Clute Institute International Academic Conference

Raja, A Senthamil, dan P Palanichamy, (2014), “Leadership styles and its impact on organizational commitment," The Journal of Commerce

Rhodin, Roni; Titik Kismiyati; Tri Margono, (2014), “Implementasi knowledge sharing sebagai upaya peningkatan efektifitas keprofesionalan pustakawan," STAIN

Robbins, Stephen. 2008. Perilaku Organisasi. Prentice Hall. PT Indeks Kelompok Gramedia. Edisi Bahasa Indonesia. Edisi Kesepuluh

Saeed, Rashid, Hafiza Hafsa Nayyab, Rab Nawaz Lodhi, Rubina Baqir, M. Abdul Rehman and Shireen Mussawar, (2013), "Impact of Retention Factors on Organizational Commitment in General Education Division of Pakistan," Middle-East Journal of Scientific Research 17 (4): 539-545, 2013

Salem, Zaneb Omer and Syed Omar Syed Agil, (2012), “The Effects of Islamic Management Ethics on Organizational Commitment of Employees in Libyan Public Banks," Australian Journal of Basic and Applied Sciences, 6(7): 260-270, 2012

Sumarno, J, (2005), "Pengaruh komitmen organisasi dan gaya kepemimpinan terhadap hubungan antara partisipasi anggaran dan kinerja manajerial," SNA VIII

Sutton, Melanie, (2006), "Emotional intelligence and competence in a knowledge citizens world," South African Journal of Information Management 